University of Nebraska - Lincoln

DigitalCommons@University of Nebraska - Lincoln

Updating the 2001 National Land Cover Database land cover classification to 2006 by using Landsat imagery change detection methods

\author{
George Xian \\ ARTS/U.S. Geological Survey, xian@usgs.gov \\ Collin Homer \\ U.S. Geological Survey, homer@usgs.gov \\ Joyce Fry \\ SGT/USGS Earth Resources Observation and Science Center, jfry@usgs.gov
}

Follow this and additional works at: https://digitalcommons.unl.edu/usgsstaffpub

Xian, George; Homer, Collin; and Fry, Joyce, "Updating the 2001 National Land Cover Database land cover classification to 2006 by using Landsat imagery change detection methods" (2009). USGS Staff -Published Research. 529.

https://digitalcommons.unl.edu/usgsstaffpub/529

This Article is brought to you for free and open access by the US Geological Survey at DigitalCommons@University of Nebraska - Lincoln. It has been accepted for inclusion in USGS Staff -- Published Research by an authorized administrator of DigitalCommons@University of Nebraska - Lincoln. 


\title{
Updating the 2001 National Land Cover Database land cover classification to 2006 by using Landsat imagery change detection methods
}

\author{
George Xian ${ }^{\mathrm{a}, *, 1}$, Collin Homer ${ }^{\mathrm{b}}$, Joyce Fry ${ }^{\mathrm{c}, 2}$ \\ a ARTS/U.S. Geological Survey (USGS) Earth Resources Observation and Science Center, Sioux Falls, SD 57198, USA \\ b USGS Earth Resources Observation and Science Center, Sioux Falls, SD 57198, USA \\ c SGT/USGS Earth Resources Observation and Science Center, Sioux Falls, SD 57198, USA
}

\section{A R T I C L E I N F O}

\section{Article history:}

Received 15 July 2008

Received in revised form 22 December 2008

Accepted 7 February 2009

\section{Keywords:}

Land cover

Change vector analysis

Normalization

Landsat imagery

Change detection

\begin{abstract}
A B S T R A C T
The recent release of the U.S. Geological Survey (USGS) National Land Cover Database (NLCD) 2001, which represents the nation's land cover status based on a nominal date of 2001, is widely used as a baseline for national land cover conditions. To enable the updating of this land cover information in a consistent and continuous manner, a prototype method was developed to update land cover by an individual Landsat path and row. This method updates NLCD 2001 to a nominal date of 2006 by using both Landsat imagery and data from NLCD 2001 as the baseline. Pairs of Landsat scenes in the same season in 2001 and 2006 were acquired according to satellite paths and rows and normalized to allow calculation of change vectors between the two dates. Conservative thresholds based on Anderson Level I land cover classes were used to segregate the change vectors and determine areas of change and no-change. Once change areas had been identified, land cover classifications at the full NLCD resolution for 2006 areas of change were completed by sampling from NLCD 2001 in unchanged areas. Methods were developed and tested across five Landsat path/row study sites that contain several metropolitan areas including Seattle, Washington; San Diego, California; Sioux Falls, South Dakota; Jackson, Mississippi; and Manchester, New Hampshire. Results from the five study areas show that the vast majority of land cover change was captured and updated with overall land cover classification accuracies of $78.32 \%, 87.5 \%, 88.57 \%, 78.36 \%$, and $83.33 \%$ for these areas. The method optimizes mapping efficiency and has the potential to provide users a flexible method to generate updated land cover at national and regional scales by using NLCD 2001 as the baseline.
\end{abstract}

(c) 2009 Elsevier Inc. All rights reserved.

\section{Introduction}

Land cover (LC) composition and change are important aspects for many scientific research and socioeconomic assessments. Data related to LC types and distributions are widely used to assess landscape condition and to monitor status and trends of ecosystem change over a specific time period (Coppin et al., 2004). Inventory and monitoring of the types and locations of land use and land cover (LULC) change provide valuable information to better understand change mechanisms and to model impacts on the environment and associated ecosystems (Homer et al., 2004; Loveland et al., 2002; Lunetta et al., 2002a,b; Xian \& Crane, 2005). Continuous, accurate, and up-to-date land cover data are important for natural resource and ecosystem management and need to be based on consistent monitoring of landscape attributes over time. However, at regional or national scales, such efforts face a number of challenges, including timely acquisition of data, the high cost of creating national products, and the

\footnotetext{
* Corresponding author.

E-mail address: xian@usgs.gov (G. Xian).

${ }^{1}$ Work performed under USGS contract 08HQCN0007.

2 Work performed under USGS contract 08HQCN0005.
}

development of appropriate analytical techniques to successfully evaluate change.

The National Land Cover Database consists of two major data releases based on a 10-year cycle. These include a circa 1992 conterminous U.S. land cover dataset with one thematic layer of land cover (NLCD 1992) (Vogelmann et al., 2001), and a circa 200150 state/Puerto Rico updated U.S. land cover database with three thematic layers including land cover, percent imperviousness, and percent tree canopy (NLCD 2001) (Homer et al., 2004; Homer et al., 2007). With these national data layers, there is often a 5-year time lag between the image capture date and product release. In some areas, the land cover can undergo significant change during production time, resulting in products that may be perpetually out of date. To address these issues, a circa 2006 NLCD land cover product (NLCD 2006) was conceived to meet user community needs for more frequent land cover monitoring (moving to a 5-year cycle) and to reduce the production time between image capture and product release. NLCD 2006 is planned to provide the user both updated land cover data and additional information that can be used to identify the pattern, nature, and magnitude of changes occurring between 2001 and 2006.

To achieve this goal in a cost-effective manner, one possible approach would be to identify areas of LC change occurring subsequent to 2001 
and to update LC data only for these areas. For the areas that have not changed, the NLCD 2001 land cover would remain the same. One advantage in monitoring LC change with remotely sensed data is that temporal sequences of images can accurately indicate spectral changes based on surface physical condition variations, assuming that digital values are radiometrically consistent for all scenes (Cakir et al., 2006). Multitemporal, medium resolution remotely sensed data can be used to identify such spectral changes and extrapolate LC types for updating LC classification over a large geographic region (Lunetta et al., 2006).

To develop a practical method for large-area change monitoring using remote sensing data, significant reduction of inter- and intraannual vegetation phenology variance and removal of image noises caused by atmospheric effects are required. Factors contributing to the potential inconsistency in measured radiance include changes in surface condition, illumination geometry, sensor calibration, and atmospheric condition (Jensen et al., 1995). For most change detection applications, variations in solar illumination conditions, atmospheric scattering and absorption, and detector performance need to be normalized (Coppin et al., 2004). Among several relative radiometric normalization methods (Furby \& Campbell, 2001; Hall et al., 1991), relative radiometric normalization techniques have proved useful in correcting data inconsistencies resulting from many different effects (Coppin \& Bauer, 1994; Collins \& Woodcock, 1996; Elvidge et al., 1995; Lu et al., 2004; Nelson et al., 2005). The normalization technique using a linear regression approach usually derives a correction factor for the subject image relative to a reference image (Singh, 1989). Most early approaches of the relative radiometric normalization were based on manually selecting time-invariant features (Elvidge et al., 1995; Yang \& Lo, 2000). Recently, a multivariate alteration detection (MAD) approach was introduced for bitemporal image change detection (Nielsen et al., 1998, 2002) and was used for selecting time-invariant pixels to normalize images (Canty et al., 2004). However, the usefulness of the normalized image obtained from the MAD method for land cover related change detection is not clear. By using normalized images for change detection, a change vector analysis (CVA) designed to interpret image transformation results by specifying the magnitude and nature of change was usually used for determining changes associated with LC change (Chen et al., 2003; Lambin \& Strahler, 1994). To achieve optimal results by using normalization and CVA, anniversary dates are often used for bitemporal change detection because they minimize discrepancies in reflectance caused by seasonal vegetation cover variations and Sun

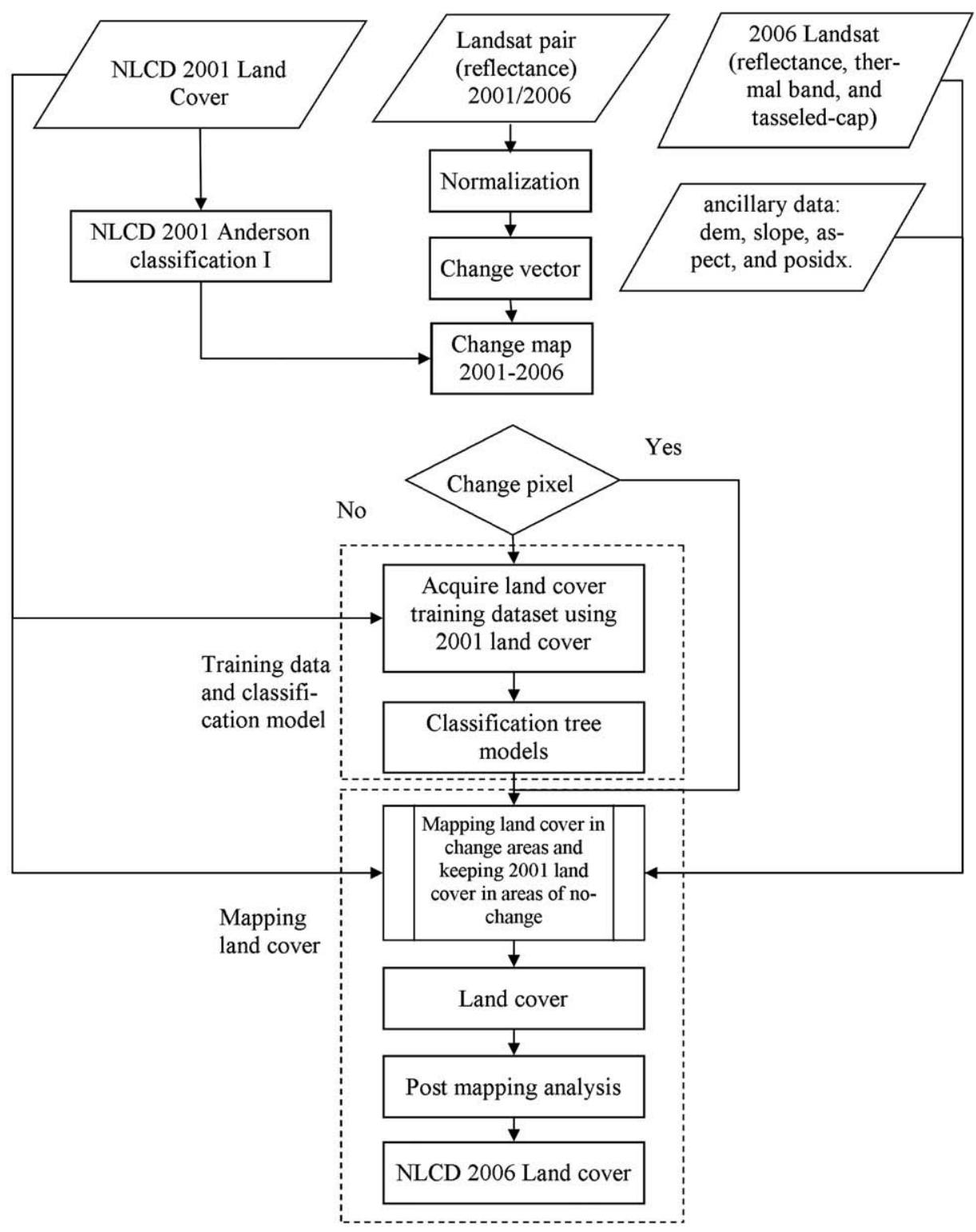

Fig. 1. Flowchart of the prototype method for NLCD 2006 updating by using change vector analysis and decision tree land cover classification algorithm. 
Table 1

Landsat image locations, paths and rows, acquisition dates, and sources.

\begin{tabular}{|c|c|c|c|c|}
\hline Location & Path & Row & Date & Landsat \\
\hline Manchester, New Hampshire & 13 & 30 & $\begin{array}{l}8 / 31 / 1999 \\
9 / 24 / 2005\end{array}$ & $\begin{array}{l}\text { ETM+ } \\
\text { TM }\end{array}$ \\
\hline Jackson, Mississippi & 22 & 38 & $\begin{array}{l}7 / 15 / 2000 \\
6 / 6 / 2006\end{array}$ & $\begin{array}{l}\text { ETM+ } \\
\text { TM }\end{array}$ \\
\hline Sioux Falls, South Dakota & 29 & 30 & $\begin{array}{l}6 / 30 / 2000 \\
6 / 23 / 2006\end{array}$ & $\begin{array}{l}\text { ETM+ } \\
\text { TM }\end{array}$ \\
\hline Seattle, Washington & 46 & 27 & $\begin{array}{l}9 / 25 / 2000 \\
9 / 2 / 2006\end{array}$ & $\begin{array}{l}\text { ETM+ } \\
\text { TM }\end{array}$ \\
\hline San Diego, California & 40 & 37 & $\begin{array}{l}10 / 4 / 2001 \\
2 / 12 / 2006\end{array}$ & $\begin{array}{l}\text { ETM+ } \\
\text { TM }\end{array}$ \\
\hline
\end{tabular}

angle differences. The phenological stability of summer and winter seasonal imagery is often best for change detection applications (Hame, 1988). However, not all radiometric variations detected from multitemporal satellite images are associated with authentic LC change. Correct identification of radiometric changes does not guarantee that these changes can be correctly classified. A thorough knowledge of existing LC condition needs to be incorporated with remotely sensed change analyses to provide useful information in determining LC change directions (Comber et al., 2004).

Here we report on the use of two dates of Landsat imagery to update NLCD 2001 land cover to circa 2006. Proposed methods involve change vector analysis to identify changed pixels, coupled with decision tree classification (DTC) trained from unchanged pixels, and label changed pixels to the updated land cover type. Methods proposed here should greatly accelerate the ability to update NLCD to circa 2006. Similar approaches were also used to produce percent impervious surface data for the five areas, and those results will be presented in a separate article.

\section{Methodology}

The proposed CVA-DTC method requires image preprocessing, image normalization, change and no-change detection, training data sampling, land cover classification, and postmapping analysis. The general procedures are summarized in the flowchart displayed in Fig. 1.

\subsection{Landsat image selection and preprocessing}

The proposed algorithm requires a two-date pair of Landsat scenes in the same path and row for change detection and land cover classification. To reduce the impacts of seasonal and phenological variation, the image pairs were selected in the same season or nearly the same season for all target areas (Table 1). The temporal ranges for most scenes were restricted to within about one month, but the San Diego scene differs by nearly four months because no cloud-free image pair was available for the same season. To satisfy the preprocessing requirement for change detection, multitemporal image registration and radiometric and atmospheric corrections were accomplished first. All images were acquired from the USGS Earth Resources Observation and Science (EROS) Center and had terrain correction applied through the National Landsat Archive Production System (NLAPS). The corrections included radiometric and geometric precision correction and had a registration error of less than $5 \mathrm{~m}$. The atmospheric corrections also were conducted by converting digital number to at the top of atmospheric reflectance using the same procedures as for NLCD 2001 (Homer et al., 2004).

\subsection{Landsat imagery normalization}

The detection of landscape change revealed by variations in surface reflectance from multidate satellite images requires radiometric correction. The relative correction approach is preferred because no in situ atmospheric data are required for the correction. To perform a relative radiometric normalization, one image is used as a reference so that the radiometric properties of the subject image are adjusted to match the reference. To update NLCD 2001 to 2006 for the entire United States, hundreds of Landsat scenes are required for change detection and LC classification. A cost-effective and operationally practical approach is needed to perform relative radiometric normalization for these scenes.

Among many normalization methods, linear regression normalization has been developed and proven as a successful approach to reveal changes in surface reflectance from multidate satellite images (Schott et al., 1988; Yang \& Lo, 2000). One fundamental premise of the method is that the radiance reaching a satellite sensor in a given spectral channel can be expressed as linear function of reflectivity. Also, the assumption that atmospheric and calibration differences between scenes are linearly related simplifies the normalization procedure so that it simply involves relating each pixel of the subject image (usually in late date) and reference image (usually in early date) band by band to produce a linear equation by a least-squares regression and can achieve an optimal performance (Yang \& Lo, 2000). In addition, the method does not require extra segmenting sample sets from images and is easy to implement. The linear equation normalization was chosen here with consideration of operational feasibility.

Accordingly, scene pairs are normalized using the following linear regression formula

$s_{i}=a_{i} x_{i}+b_{i}$

where $x_{i}$ is the digital number (DN) of band $i$ in the image that is to be normalized (subject image) and $s_{i}$ is the normalized DN of band $i$ in the subject image, $a_{i}$ is the slope or gain, and $b_{i}$ is the intercept or offset. The equation accounts for the difference in the mean and variance between radiance values in different dates. The transformation coefficients $a_{i}$ and $b_{i}$ are computed from a linear regression carried out on two radiometric images, in which clouds and shadows are excluded, for the whole scene by $a_{i}=V_{\mathrm{s}, i} / V_{\mathrm{r}, i}$ and $b_{i}=M_{\mathrm{ri}}-a_{i} M_{\mathrm{s}, i}$, where $V_{\mathrm{s}, i}$ and $V_{\mathrm{r}, i}$ are the variances of subject and reference images in band $i$, respectively, and where $M_{\mathrm{s}, i}$ and $M_{\mathrm{r}, i}$ are the means of subject and reference images in band $i$, respectively.

\subsection{Change vector analysis}

Change vector analysis focuses on multivariate change detections for two-date images. To implement CVA, the normalized and reference images are used to calculate a $\mathrm{CV}$ that represents the spectral feature differences that may represent changes in land use and land cover types between two dates. If a pixel's values in two images on dates $t_{1}$ and $t_{2}$ are represented by two vectors $\mathbf{R}$ and $\mathbf{S}$, respectively, vectors are expressed as

$\mathbf{R}=\left[\begin{array}{c}r_{1} \\ r_{2} \\ \vdots \\ r_{n}\end{array}\right], \mathbf{S}=\left[\begin{array}{c}s_{1} \\ s_{2} \\ \vdots \\ s_{n}\end{array}\right]$

where $n$ is the number of bands. A CV is then determined by

$\Delta \mathbf{V}=\mathbf{R}-\mathbf{S}=\left[\begin{array}{c}r_{1}-s_{1} \\ r_{2}-s_{2} \\ \cdots \\ r_{n}-s_{n}\end{array}\right]$

The change magnitude is calculated with

$|\Delta \mathbf{V}|=\left[\left(r_{1}-s_{1}\right)^{2}+\left(r_{2}-s_{2}\right)^{2}+\cdots+\left(r_{n}-s_{n}\right)^{2}\right]^{1 / 2}$ 


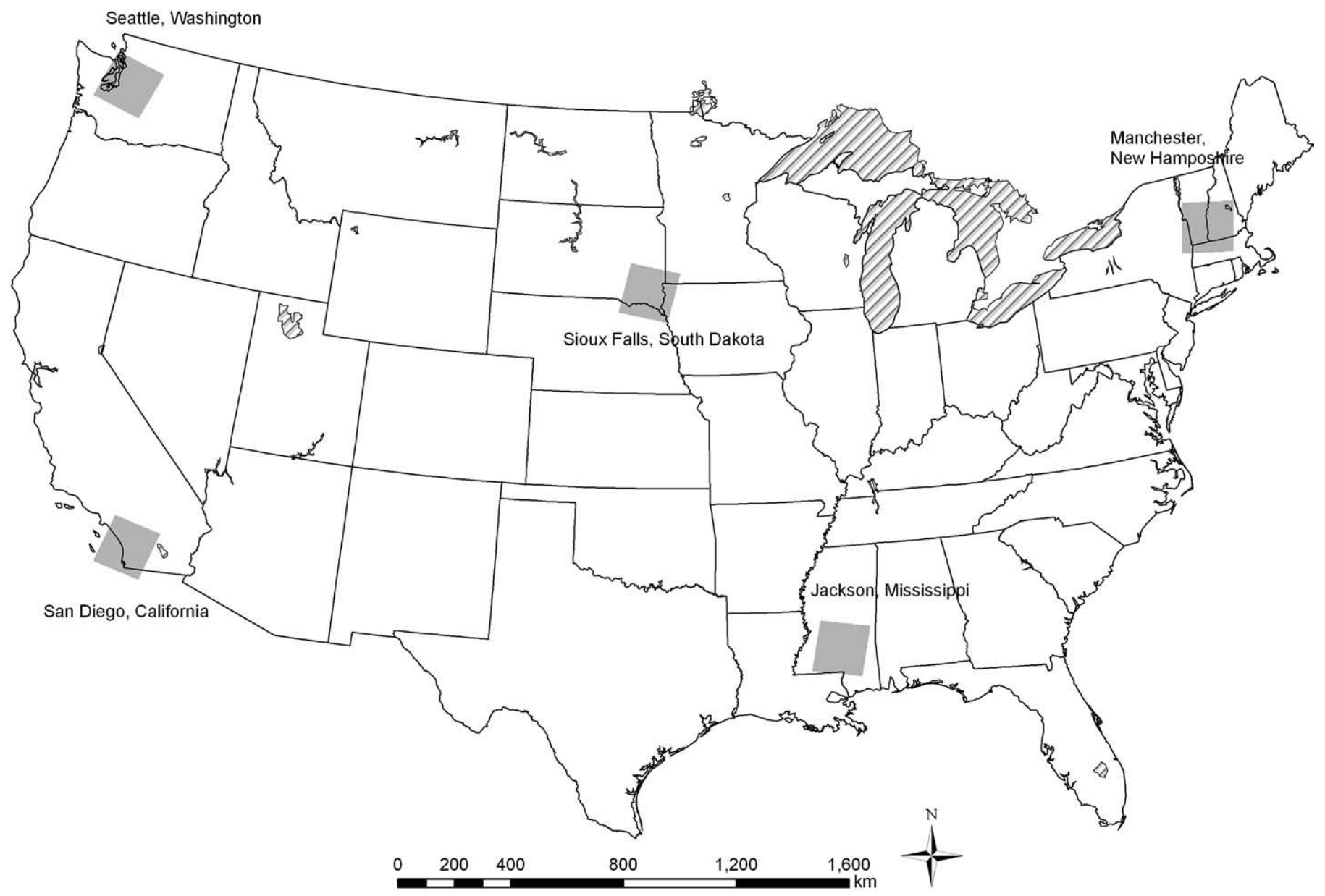

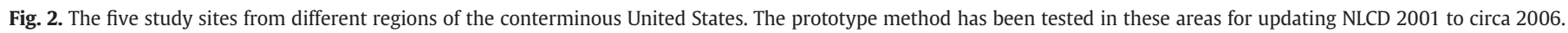

where $\|\Delta \mathbf{V}\|$ represents the total differences and includes all the changed or unchanged information between $t_{1}$ and $t_{2}$ for a given pixel. Generally, a greater $\|\Delta \mathbf{V}\|$ indicates a higher possibility of change in land cover type, and a specific threshold is usually used to determine pixels of change or no-change.

\subsection{Threshold for bitemporal change detection}

Usually, the selection of a threshold to identify a changed or unchanged pixel can be done empirically through experience or objectively through an optimal threshold search algorithm (Chen et al., 2003). Typically, a single threshold is used for a whole scene to determine whether the physical characteristics within a pixel are changed or not changed between two dates (Morisette \& Khorram, 2000). However, LC type is not unique within a Landsat scene footprint, and the single threshold obtained from CVA is not always appropriate to segregate areas of change or no-change (CNC). For example, the dynamic range of $\|\Delta \mathbf{V}\|$ from agricultural land might be larger than that of clear-cut areas in forestland. If a single threshold is used to segregate areas of change or no-change for all land cover types, then changed areas can be either overextracted or underextracted. Here, we propose a multithreshold approach to define pixels of change or no-change by assuming that thresholds determined by the magnitudes of the change vector depend on different land cover categories, and multiple thresholds are necessary for change determination. Generally, if the change vector magnitude of a pixel for a certain land cover type is larger than the mean plus an adjustable parameter multiplied by the standard deviation of the histogram for the specific LC category, the pixel is defined as a changed pixel; otherwise, the pixel label is unchanged. To simplify the class legend during threshold calculations, the NLCD 2001 product is recategorized to eight LC classes according to the Anderson Level I classification (Anderson et al., 1976). The condition is defined by following constraints

$$
C V_{j}(x, y)=\left\{\begin{array}{cr}
\text { change } & \text { if }\left|\Delta \mathbf{V}_{j}(x, y)\right| \geq\left|\overline{\mathbf{V}_{j}}\right|+a_{j} \sigma_{j} \\
\text { no-change } & \text { if }\left|\Delta \mathbf{V}_{j}(x, y)\right|<\left|\overline{\mathbf{V}_{j}}\right|+a_{j} \sigma_{j}
\end{array}\right.
$$

where $j$ represents an LC class, $\left\|\overline{\mathbf{V}}_{j}\right\|$ is the mean of change vector $\left(C V_{j}\right)$ for the LC type $j, \sigma_{j}$ is the standard deviation of the $C V_{j}$, and $a_{j}$ is an adjustable parameter. Morisette \& Khorram (2000) demonstrated that the optimal range of $a_{j}$ is from 0.0 to 1.5 for a single threshold. Thus, the range of $a_{j}$, depending on the LC type, is retained from 0.0 to 1.5 .

\subsection{Training dataset}

Change pixels are classified by using the same decision tree classification algorithm used for the NLCD 2001 LC classification. A training dataset is required to train the model to build up relationships for different LC categories. All training data are selected through 

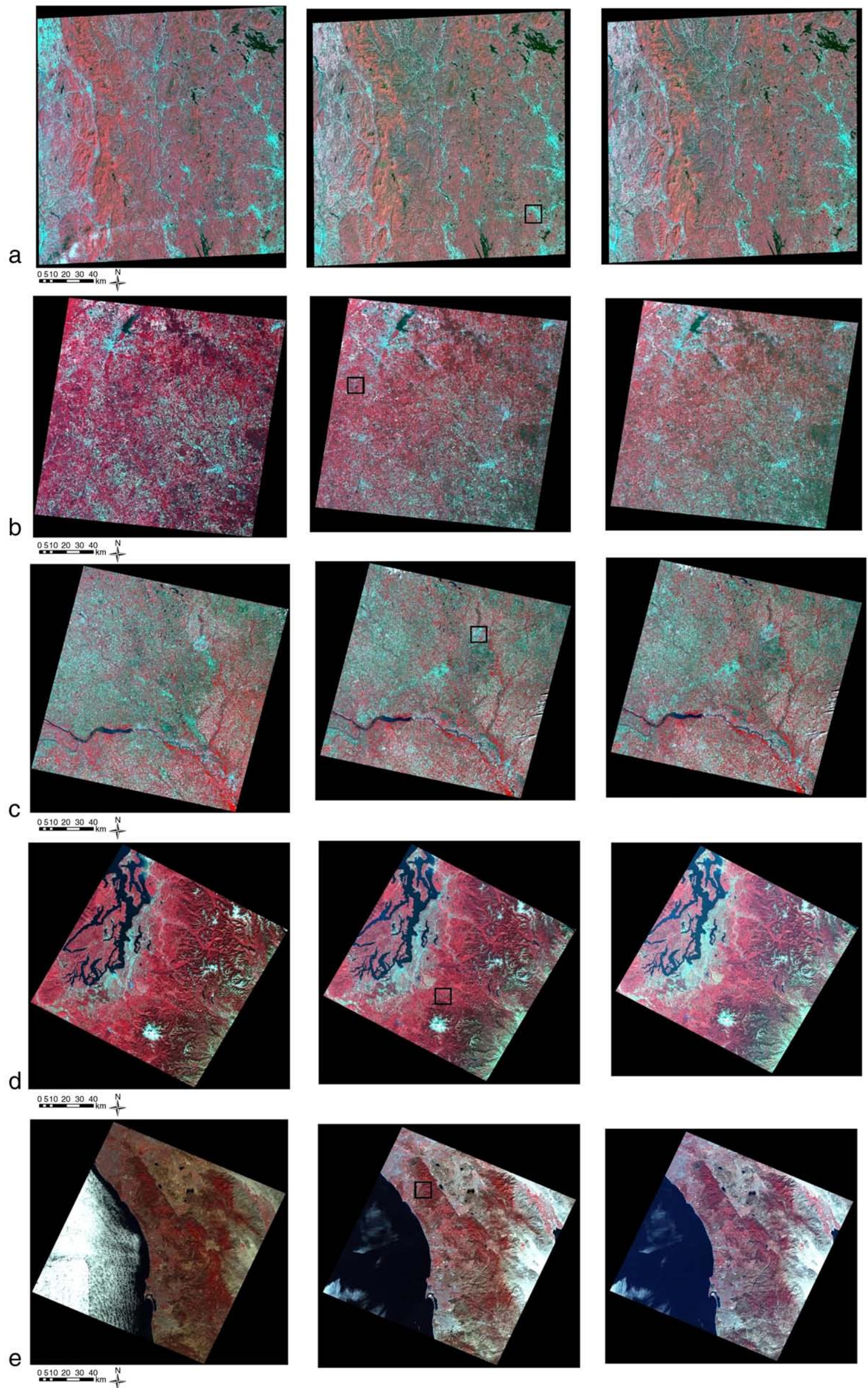
randomly stratifying samples from areas designated as unchanged to assure that the same classification accuracies as NLCD 2001 are kept in the training dataset. Training samples include all LC classes with the number of samples for any particular LC class held proportional to the total number of pixels in that class. Therefore, an adequate number of pixels for each LC class is included in the training dataset for a study area. These samples are then used to create an environment file that serves as the dependent variable for the decision tree model. Independent variables used as input to the model are 2006 Landsat reflectance (bands 1-5 and 7), the thermal band, the tasseled-cap derivative, and digital elevation data. Separate and unique classification models are developed for each study area.

\section{Study area descriptions}

To examine the proposed algorithms, five study areas were selected: the New England area including parts of New Hampshire, Vermont, Massachusetts, and New York; southern Mississippi and the eastern part of Louisiana; eastern South Dakota and parts of Nebraska, Iowa, and Minnesota; Washington; and southern California. Accordingly, five Landsat scenes were acquired from these locations. Each scene was named after a major city included within the scene footprint: Manchester, New Hampshire; Jackson, Mississippi; Sioux Falls, South Dakota; Seattle, Washington; and San Diego, California. Geographic locations and spatial coverage of these scenes are displayed in Fig. 2. Table 1 presents details of paths and rows, acquisition dates, and locations for each Landsat scene. Areas covered by the five scenes have a wide range of LC types and represent the varying characteristics of ecoregions associated with NLCD 2001 mapping zones. The study areas contain 18 or $21 \%$ of Level III ecoregions of the conterminous United States (Omernik, 2004). These areas were selected because they experienced both natural and anthropogenic disturbances and contained all LC components for calibrating and validating the algorithm for LC change classification.

The first test area was within the Manchester scene in the New England region, located in the northeastern United States. More than $74 \%$ of the areal land is forestland with over 35\% deciduous forests according to NLCD 2001 (all LC information is referred as NLCD 2001 hereafter). Agricultural and urban lands are the second and third largest LC types, respectively, in the region. Agricultural lands are concentrated in the southern and western parts of the region, and forestlands are widespread.

The second test area was within the Jackson scene in southern Mississippi, located in the southeastern United States. The largest LC type in the region is forest with evergreen forest covering more than $25 \%$ of the land. The warm and humid climate makes vegetation canopies abundant in the region. Agriculture and shrub are the second and third largest LC types, respectively. Forest and agricultural lands are widely distributed in the region.

Our third test area was within the Sioux Falls scene in southeastern South Dakota, northeastern Nebraska, southwestern Minnesota, and northwestern Iowa within the Midwestern region of the United States. The regional landscape contains about 74\% agricultural land (with 60\% cultivated croplands), about $13 \%$ grasslands, and widely distributed urban areas surrounded by agriculture. The seasonal and phenological variations from agriculture and grasslands presented a significant challenge for LC change detection and classification.

The fourth test area was within the Seattle scene in Washington state, located in the northwestern corner of the United States. Major cities in the area include Seattle and Tacoma. Over 56\% of the land is classified as forestland with about $48 \%$ evergreen forest. The second largest LC type is urban, covering more than $10 \%$ of the land. Most urban land is distributed along the Interstate 5 corridor and concentrated in the Seattle and Tacoma areas. Shrubland is the third largest LC type and covers more than $9 \%$ of the land.

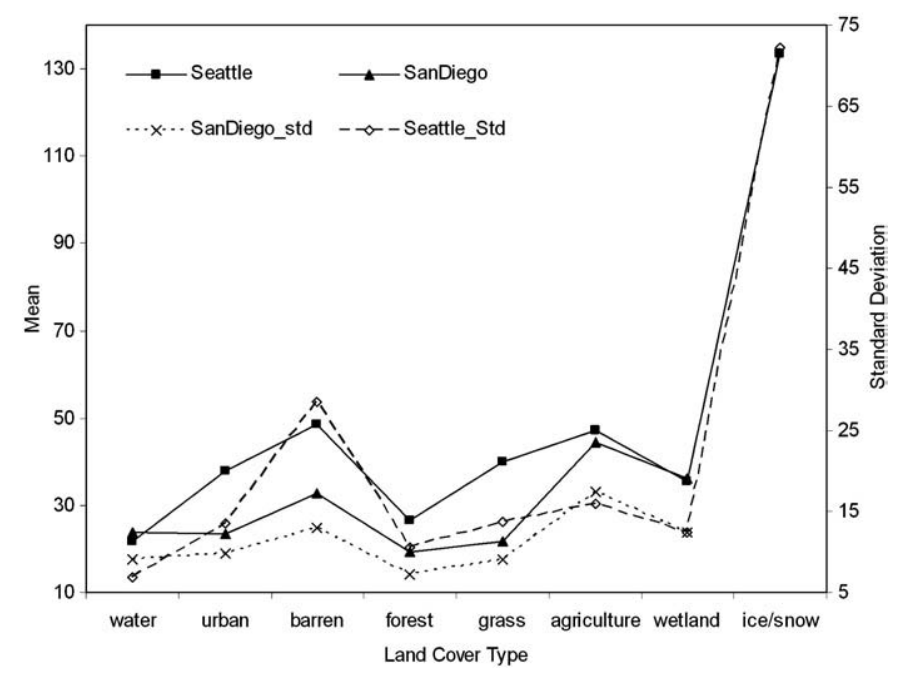

Fig. 4. Means and standard deviations of change vectors derived from different land covers determined by Anderson Level I classification in the Seattle and San Diego areas.

The fifth test area was within the San Diego scene in southern California, located in the southwestern corner of the United States. Major metropolitan areas include San Diego and southern Los Angeles. The first three largest LC types are shrubland, urban areas, and grassland covering about $48 \%, 25 \%$, and $14 \%$ of the land, respectively. A large part of the urban land is distributed along the coast from the northwest to the south. In contrast, most shrublands and grasslands are in mountain areas on the eastern part of the region where a few forestlands are also observed. Most coastal areas are well developed and new urban developments are anticipated off the coast on lands that were covered by shrub and grass in 2001 .

\section{Results}

\subsection{Normalization and change detection}

After the linear regression was performed for each image pair of selected paths and rows, normalization procedures were applied to the subject image to obtain a normalized image. To facilitate the visual comparison, Landsat image pairs comprised of bands 4, 3, and 2 and normalized images were produced for the five study areas (Fig. 3 ). Visual inspections for all images indicated that there were more spectrally variant patches in the Jackson and Sioux Falls scenes than in other scenes. Many variant patches were related to temporal changes in vegetation conditions associated with agricultural activities.

The CVs calculated from normalized and reference images indicated that CVs usually have large dynamic ranges on different landscapes. Fig. 4 demonstrates values of CV and associated standard deviations for different LC types in Anderson Level I in the Seattle and San Diego areas. Accordingly, dynamic ranges of CVs vary with LC types; for example, water has a relatively small mean CV because of the existence of a large water body that has relatively small temporal variation in reflectance. Both mean and standard deviation of CV for the barren land are relatively large, indicating large spectral variation, especially apparent on high elevation mountains of the Seattle region. In addition, the forest has relatively small means of CV for both areas, and snow or ice has the largest mean and standard deviation of CV for the Seattle area. Clearly, multiple thresholds based on LC types were necessary for segregating pixels that experienced true physical changes but had small CVs compared to those that had false physical change but had large CVs. Areas of CNC for all five study regions were determined by applying multiple thresholds for CV images.

To visually inspect CV and areas of CNC in detail, pairs of Landsat images, CVs, and final images of CNC are displayed (Fig. 5) for the five 
a
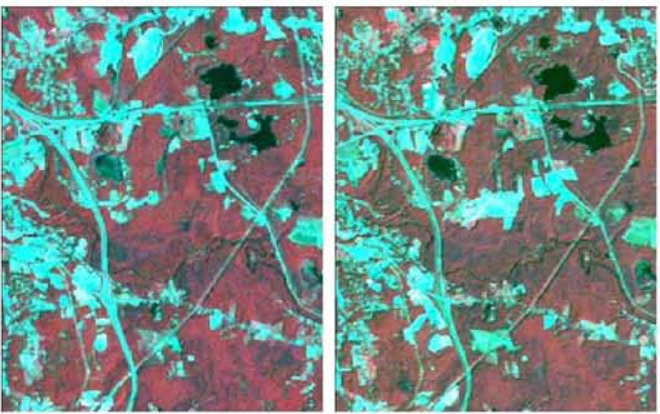

b
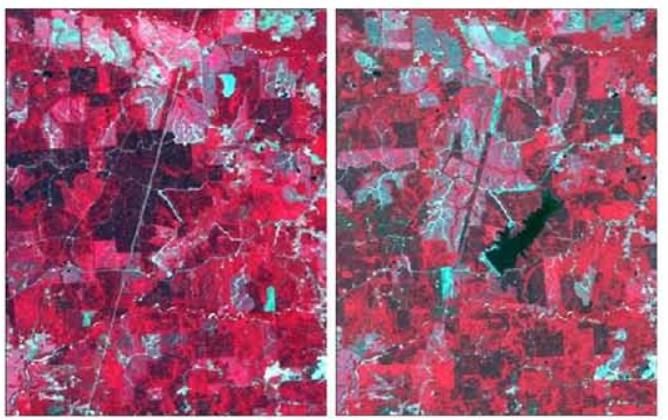

C
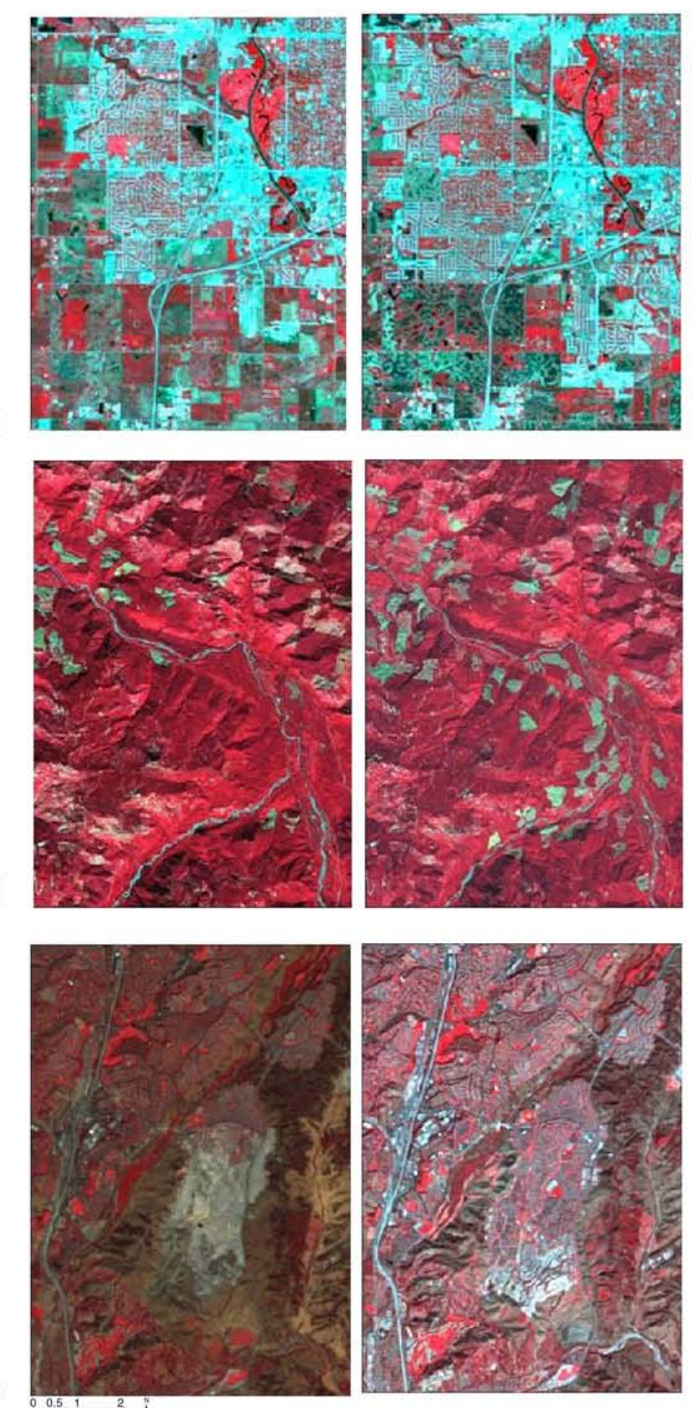
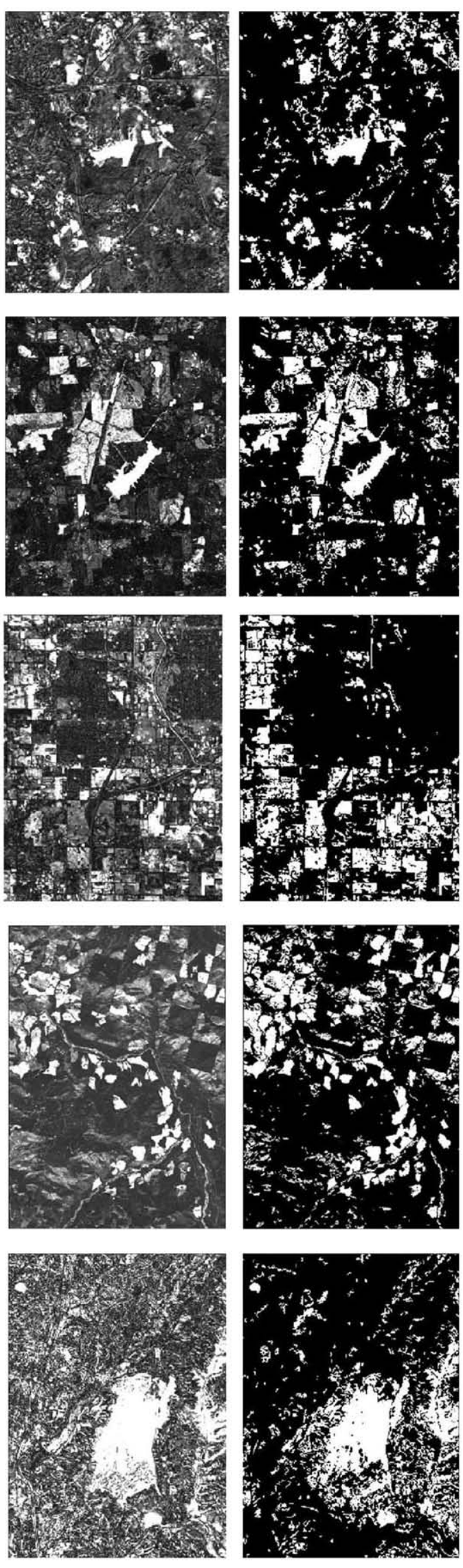

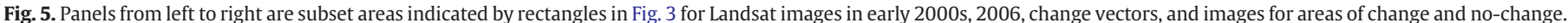
Panels from top to bottom are portions of the Manchester (a), Jackson (b), Sioux Falls (c), Seattle (d), and San Diego (e) areas. 

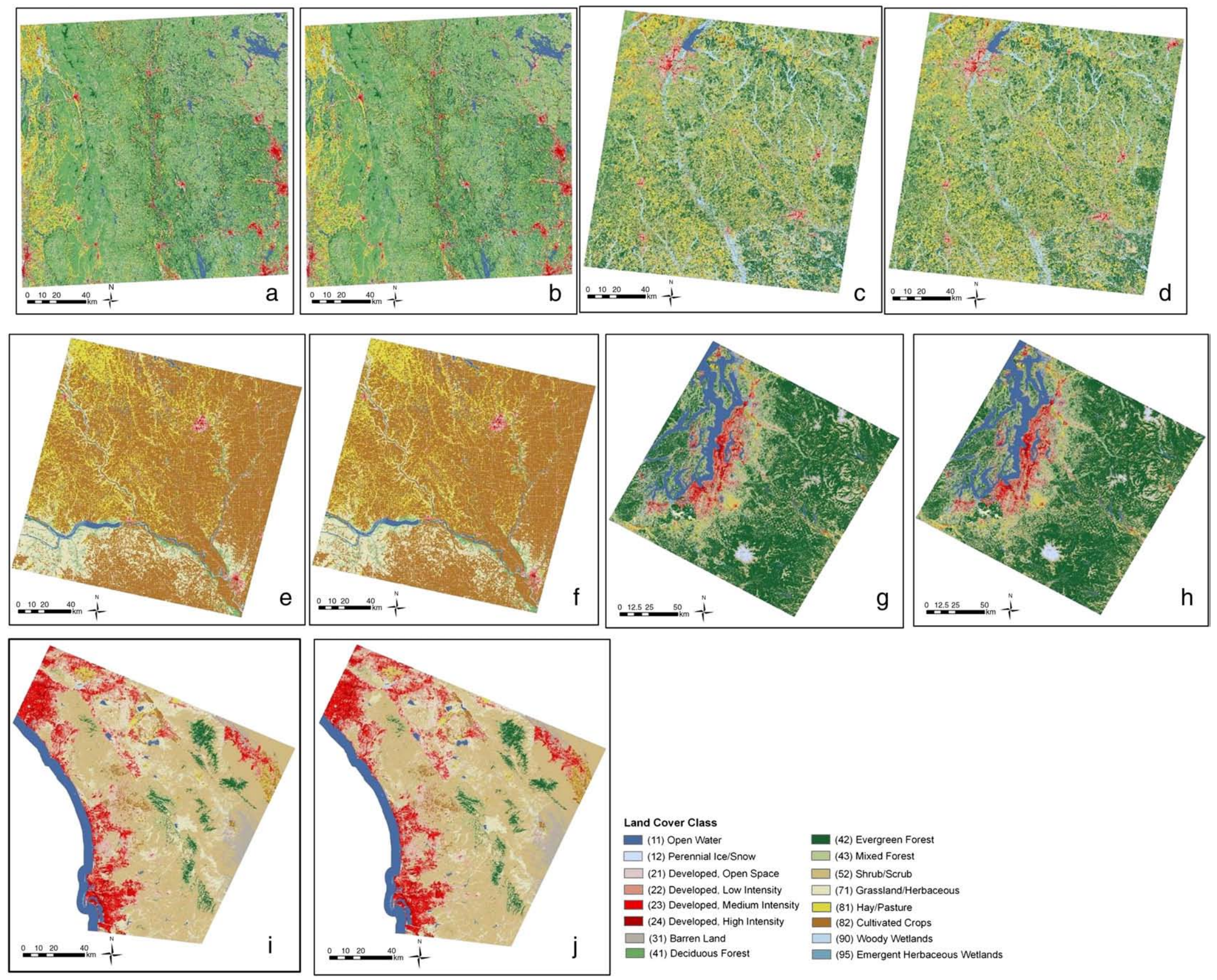

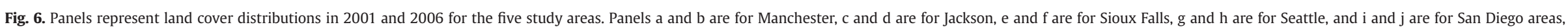
respectively. 


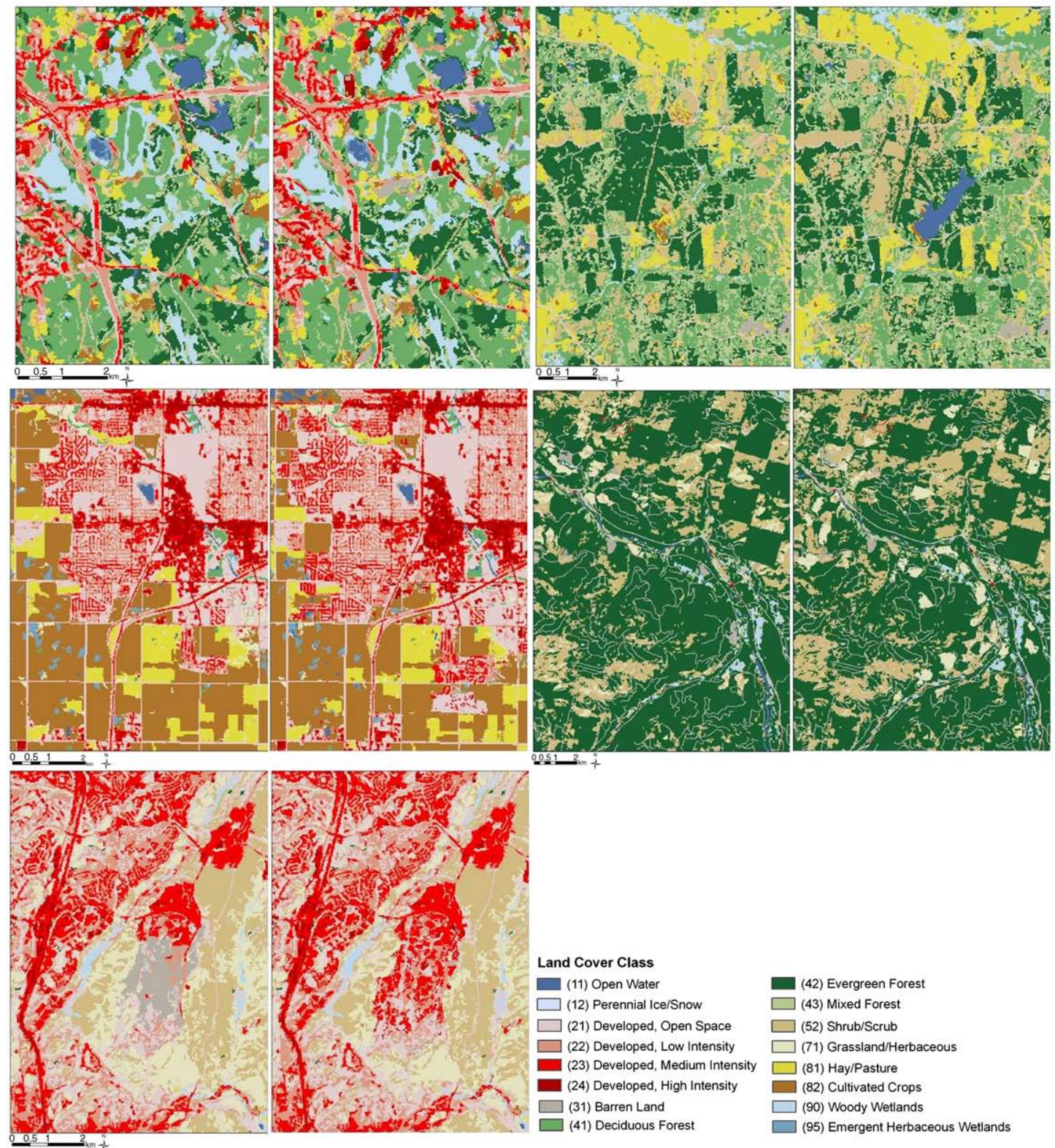

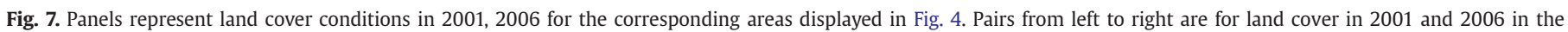
Manchester, Jackson, Sioux Falls, Seattle, and San Diego areas, respectively.

small areas defined by rectangles in Fig. 3. Changes in the forestlands observed from reflectance images are appropriately labeled in both the Manchester and Seattle areas (top and next to the bottom panels). A new reservoir and nearby forest disturbances in the Jackson scene are identified in changed areas (the second panels). Changes associated with urban development in both the Sioux Falls and San Diego scenes are also identified (the third and bottom panels). Generally, pixels having relatively large magnitudes for CV of a certain land cover type were labeled as changed areas, and pixels having relatively smaller magnitudes were classified as unchanged areas. These images of $\mathrm{CNC}$ were formatted as binary images and used as mask files for further LC classifications.

\subsection{Land cover classification}

The NLCD 2001 Anderson Level II LC product was used as a baseline for acquiring training datasets from unchanged pixels for the five study areas. The modeling results, having cross-validation errors retained within $4 \%$ to $10 \%$, were used to update LC status to the nominal date of 2006 for the five study areas. Both 2001 LC and newly updated 2006 LC images for these areas are displayed in Fig. 6. In the Manchester scene (Fig. 6a and b), land cover changes are observed in the region due to the forest harvest and replanting cycle, as well as new urban development. Forest harvesting usually implemented clear-cut or partial clear-cut (thinning) on industrial and private forestlands. Meanwhile, some cutting areas in the early 2000s are recovered from clear-cut patches to shrublands or partial-cut patches to forestlands in the 5-year period. In the Jackson scene (Fig. $6 \mathrm{c}$ and d), the forest harvest and replanting cycle frequently changes LC conditions in the region. With optimal climate conditions for forest regrowth, trees can grow about 1 to $1.5 \mathrm{~m}$ per year (Dolan et al., 2007), allowing visible forest recovery in harvested areas within a 5-year period. Other major LC changes are associated with agricultural activities in the region. In the Sioux Falls region (Fig. 6e and f), rotation 
between cultivated cropland and hay/pasture cropland might cause many false changes viewed from the satellite sensor. Other apparent changes are from urban developments that typically consume surrounding agricultural land. The Seattle region experienced apparent LC changes caused by both urban development in suburban areas and forest harvest (Fig. $6 \mathrm{~g}$ and $\mathrm{h}$ ). Many new urban developments occur on both agricultural and forestlands of the region. In the San Diego area (Fig. 6i and j), most landscape change was related to urban development to meet growing population in the region. In addition, wildland fires might also change the landscape condition because of regional dry climate in summer.

Fig. 7 depicts pairs of 2001 and 2006 LC images for the same areas displayed in Fig. 5. In the Manchester scene, changes in the evergreen forestland are updated (the first pair in Fig. 7). The second pair in Fig. 7 indicates that a new reservoir and nearby forestland changes in the Jackson scene are captured and classified in the 2006 LC image. In the Seattle scene, most changes from new forest canopies recovering from early forest-cutting and new forest-cutting areas are observed and classified. The latter usually are labeled as shrub or grasslands (the fourth pair in Fig. 7). Many change patches on the edges of cities in the Sioux Falls and San Diego areas are classified as urban lands as new developments push into these areas (the third and fifth pairs in Fig. 7). However, changes between agricultural types are restricted to have conservative changes because many of the other changes might be caused by the annual rotation of agricultural land.

The overall regional LC changes between 2001 and 2006 were assessed by calculating change pixels from the two-date LC images. Table 2 lists percent changes of land use and land cover for the five areas. Both the largest and smallest LC classes in two dates are also listed. Among them, LC change in the Jackson area has the largest change rate of $10.27 \%$, while the Manchester area has the smallest change rate of $4.28 \%$ between two dates. The largest LC types in 2001 are still the same in 2006 in each study area although their spatial extents vary $0.3-2.0 \%$ in these regions.

\section{Accuracy assessment}

Several verification processes were conducted to verify accuracies of CNC detection and LC classification for the five areas.

\subsection{Statistic sensitivity test and the assessment for CNC areas}

The determination of areas of CNC was important for successfully updating LC classification. Accurate change identification assured that the training dataset was selected from unchanged areas for decision tree models. To assess improvements for the segregation of pixels of CNC by using normalized images and CVA, sensitivity tests were conducted.

The sensitivity test was designed to test the null hypothesis that the difference between the two averages was zero if the experiment were repeated many times. A paired $t$-test was performed to assess whether the average of these differences was significantly different from zero by defining $\delta$ as the true mean of differences between random variables $y_{1}$ and $y_{2}$ that were observed with matched pairs of experimental conditions. The $\delta$ would be zero if the populations from $y_{1}$ and $y_{2}$ were equal. A 95\% confidence interval of the $\delta$ then is expressed as

$\bar{d}-t_{n, 0.05 / 2} S_{d}<\delta<\bar{d}+t_{n, 0.05 / 2} S_{d}$

where $\bar{d}$ and $S_{d}$ are the average of differences between paired observations and the standard error of the average difference, respectively. The value of $t$ is computed using the $t$-distribution. If the $95 \%$ confidence interval for these averages did include zero, the difference was not significant at $95 \%$ confident level.

Three hundred sample points randomly collected from each changed and unchanged area of a reference change and no-change image, which was determined by comparing the 2001 and 2006 LC classifications and labeling areas as no-change if two-date LC types were the same, were used to calculate reflectance differences between 2001 images and 2006 un-normalized images, as well as 2006 normalized images from CNC areas. The differences for each pair of images were averaged to have the value of $\bar{d}$ and examined to decide whether they could confidently be declared as small or large. For unchanged pixels, we expected near-zero differences because reflectance had no or small variation if subjects had no change in their physical characteristics. For changed pixels, we expected larger-than-zero differences because changes in LC characteristics also altered reflectance received by the satellite. Therefore, for unchanged areas, it was highly confident that the difference between the two time collections was small if the confidence interval did include the zero. For changed samples, the differences between two-date images were significant at 95\% confidence level if intervals did not include zeros.

The results of the sensitivity test performed for the five study areas are displayed in Fig. 8, which represents six-band spectral differences between reference, two-date un-normalized images, and normalized images from unchanged pixels. All normalized images had zeros in confidence interval differences for unchanged areas, indicating insignificant differences at the 95\% confidence level and high similarities between two-date images. However, un-normalized image pairs had only a few bands showing such insignificant differences. Normalized images showed a superior advantage for unchanged pixel detection. Nevertheless, the sensitivity tests for changed areas did not have the similar significant patterns because several band differences included zeros in confidence intervals for both normalized and un-normalized images, although the latter showed one or two band differences falling in the $95 \%$ confidence intervals without zeros. Detection for changed areas was more complicated than that for unchanged areas because many areas might not experience real LC changes regardless of large spectral differences.

A scatterplot for spectral differences of six-band from the San Diego scene is also included (Fig. 9). The plot conducted from 300 random samples in the unchanged area indicated that normalization reduced differences between reference and subject images for the unchanged area. We also conducted an error analysis for the change and no-change determination by randomly stratifying 2400 sample points from both change and no-change areas of the reference change

Table 2

Regional land cover changes between 2001 and 2006.

\begin{tabular}{|c|c|c|c|c|c|}
\hline Location & $\begin{array}{l}2001 \text { the largest land } \\
\text { cover class (\% to the total) }\end{array}$ & $\begin{array}{l}2001 \text { the smallest land } \\
\text { cover class (\% to the total) }\end{array}$ & $\begin{array}{l}2006 \text { the largest land cover } \\
\text { class (\% to the total) }\end{array}$ & $\begin{array}{l}2006 \text { the smallest land } \\
\text { cover class (\% to the total) }\end{array}$ & $\begin{array}{l}2001-2006 \text { total } \\
\text { change }(\%)\end{array}$ \\
\hline Manchester & Deciduous forest (34.47) & Barren land $(0.22)$ & Deciduous forest (33.97) & Grassland $(0.18)$ & 4.28 \\
\hline Jackson & Evergreen forest (25.29) & Barren land (0.14) & Evergreen forest (25.0) & Emergent herbaceous wetland $(0.12)$ & 10.27 \\
\hline Sioux Falls & Cultivated crops (60.93) & Mixed forest $(0.02)$ & Cultivated crops (62.91) & Mixed forest $(0.03)$ & 4.53 \\
\hline Seattle & Evergreen forest (48.17) & Cultivated crops (0.35) & Evergreen forest (46.78) & Cultivated crops (0.37) & 6.05 \\
\hline San Diego & Shrub (45.27) & Deciduous forest $(0.01)$ & Shrub (45.75) & Deciduous forest $(0.01)$ & 5.48 \\
\hline
\end{tabular}

The change percent for a specific land cover type represents the change area to the total area of that land cover. 

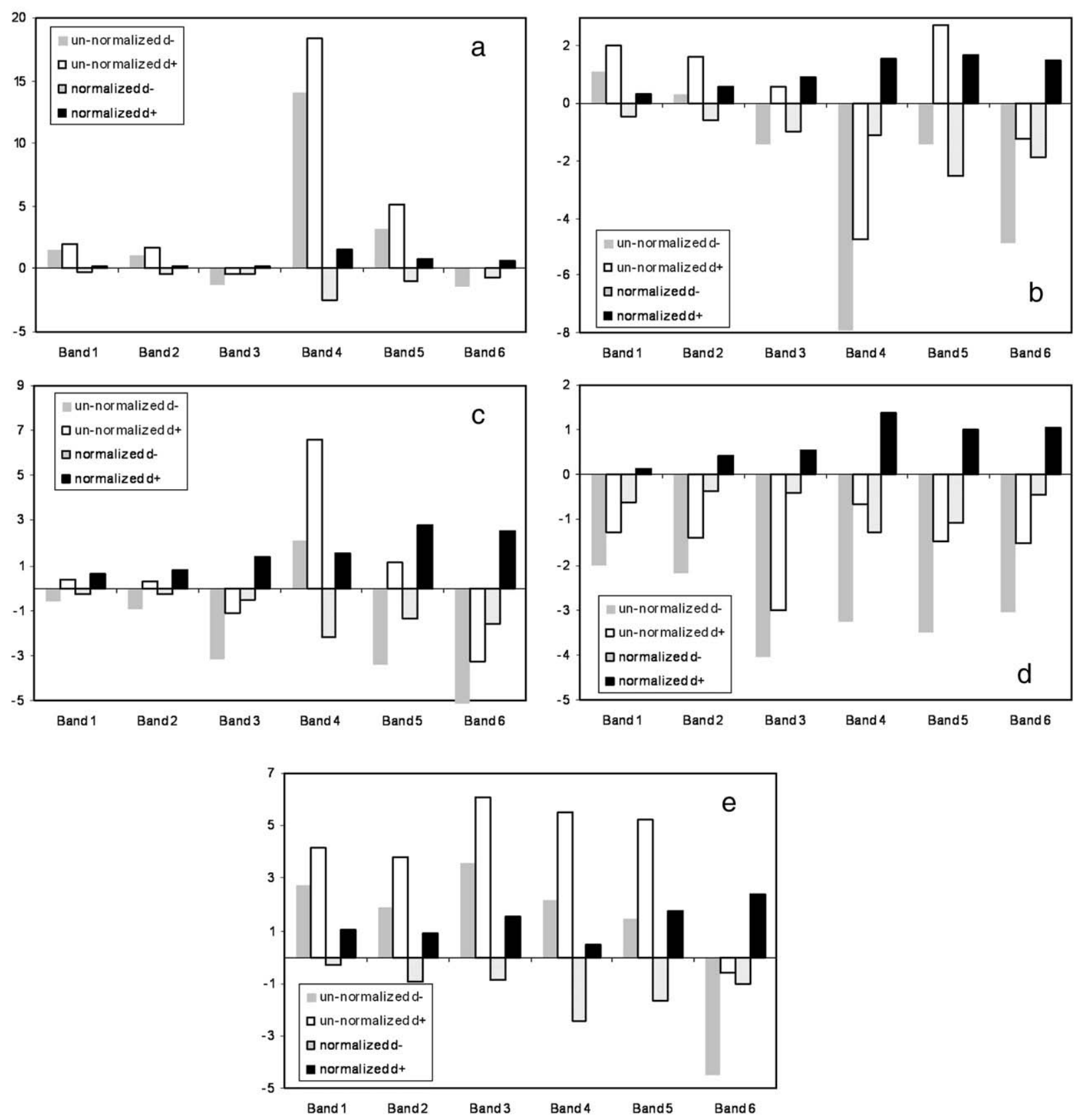

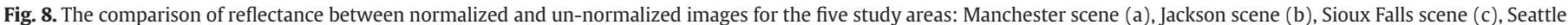
scene (d), and San Diego scene (e). The $y$-axis represents the $95 \%$ confidence intervals defined as $d-\left(\bar{d}-t_{n, 0.05 / 2} S_{d}\right)$ and $d+\left(\bar{d}+t_{n, 0.05 / 2} S_{d}\right)$ in Eq. $(6)$.

and no-change image from the Sioux Falls scene. Table 3 displays an error matrix for change and no-change determination for the area. A relatively high overall accuracy of $94.2 \%$ and a Kappa coefficient of 0.8577 were obtained.

\subsection{Accuracy curves for change detection using multiple thresholds}

The multiple thresholds determined by LC types and used for CNC detection were set up by different adjustable parameters $\left(a_{j}\right.$ in Eq. (5)). To compare with change detection using a single threshold, binary products of $\mathrm{CNC}$ obtained using a single type threshold (STT) for all LC types, multitype thresholds with a unique adjustable parameter (MTUAP) for all LC types, and multitype thresholds with different adjustable parameters (MTDAP) for different LC types were compared.
The assessments were conducted by comparing CNC pixels obtained from CVA with CNC samples from a reference image obtained from comparing two-date LC classification. Six hundred randomly selected samples from areas of CNC of the Seattle area were used to calculate the overall accuracies and Kappa coefficients. Fig. 10 displays the comparisons of overall accuracy and Kappa coefficient. The multiple thresholds with different adjustable parameters for different LC types achieved the best performance in both overall accuracy (0.91) and Kappa coefficient (0.81). Less accurate results were observed from the single threshold test in which the largest overall accuracy (0.89) and Kappa coefficient (0.79) were observed at 0.5 standard deviation level. The results from using multiple thresholds with the same adjustable parameter for different LC types had the lowest accuracy in which the largest overall accuracy (0.87) and Kappa coefficient (0.73) were obtained at 0.5 standard deviation level. 

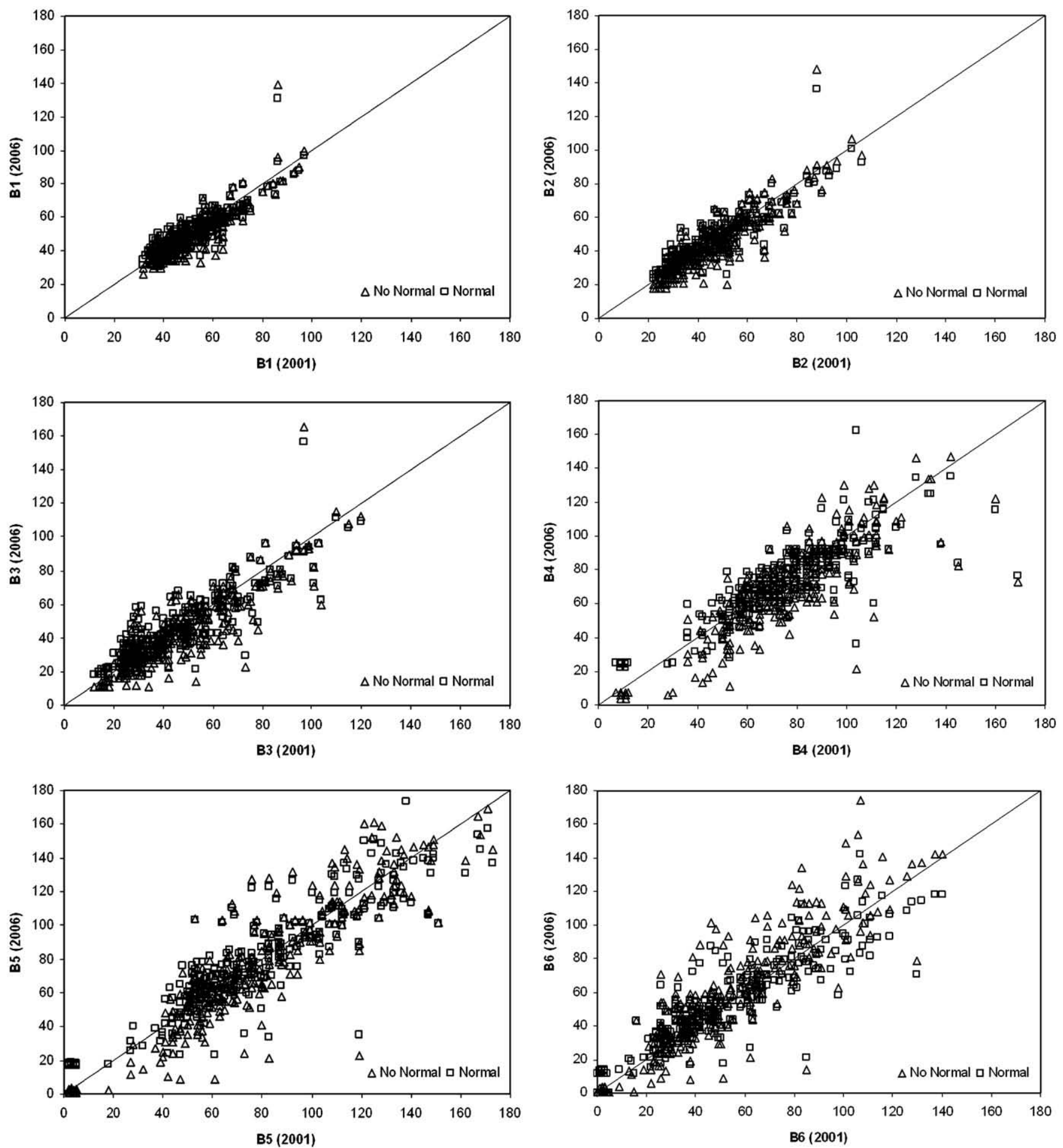

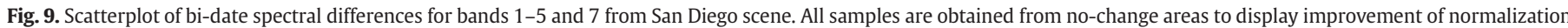
for change and no-change determination.

\subsection{Land cover accuracy}

To inspect the performances of LC classification for the five study areas, accuracies of change type classification were estimated from analysis of sample pixels randomly stratified from the 2006 LC images. More than 100 random samples including all land use and land cover types were chosen from each of the five 2006 LC images. The corresponding reference ground truth data were produced from visual interpretations of both 2006 Landsat images and 4-m resolution natural color images acquired in 2006 and organized by the National
Agriculture Imagery Program (NAIP) to label land cover types. Table 4 presents the classification error matrixes and accuracies for all LC types. Overall accuracies and Kappa coefficients were $83.33 \%$ and 0.82 for Manchester, $78.36 \%$ and 0.76 for Jackson, $88.57 \%$ and 0.87 for Sioux Falls, $78.32 \%$ and 0.76 for Seattle, and $87.50 \%$ and 0.86 for San Diego. The Sioux Falls, San Diego, and Manchester areas had relatively high overall accuracies and large Kappa coefficients. The other two study areas, Jackson and Seattle, had relatively low overall accuracies and small Kappa coefficients. Generally, overall accuracy and Kappa coefficients for the five areas exceeded $78 \%$ and 0.7 , respectively, 
Table 3

Error matrix for change and no-change detection from Sioux Falls scene.

\begin{tabular}{|c|c|c|c|c|c|}
\hline & & Referenc & change & & \\
\hline & & Change & No-change & Sum & $\begin{array}{l}\text { Commission } \\
\text { error }\end{array}$ \\
\hline Classified & Change & 639 & 111 & 750 & $14.80 \%$ \\
\hline change & No-change & 34 & 1716 & 1750 & $1.94 \%$ \\
\hline & Sum & 673 & 1827 & 2500 & \\
\hline & Omission error & $5.05 \%$ & $6.08 \%$ & & \\
\hline & Overall accuracy & & $94.20 \%$ & Kappa coefficient & 0.8577 \\
\hline
\end{tabular}

indicating that the prototype method is accurate and effective for LC change type classification.

\section{Discussion}

It is always a challenge to reliably detect land cover change using remote sensing data for a large geographic extent - especially in a cost-effective way. The land cover results of this new prototype method attempt to strike the balance between product accuracy and affordability. It appears that the CVA-DTC algorithm is capable of updating NLCD land cover using these image change detection and classification procedures. This method requires several steps to incorporate pre-classification spectral change detection with DTC for land cover change detection and change type classification. First, two paired images from 2001 and 2006 over the same satellite path and row are normalized. Next, the normalized and reference images are used to calculate CVAs for pre-classification spectral change thresholding. Finally, multiple thresholds based on NLCD 2001 land cover baseline information were used to segregate pixels of change and no-change from change vectors. Compared with other existing radiometric spectral change detection methods (Coppin et al., 2004; Yang \& Lo, 2000), this CVA method is easy to operate and efficient to implement. Among several methods for relative radiometric normalization of multispectral images (Du et al., 2002; Furby \& Campbell, 2001; Yang \& Lo, 2000), the method proposed by Canty et al. (2004) was best able to normalize multispectral images in automated procedures. This method used the multivariate alteration

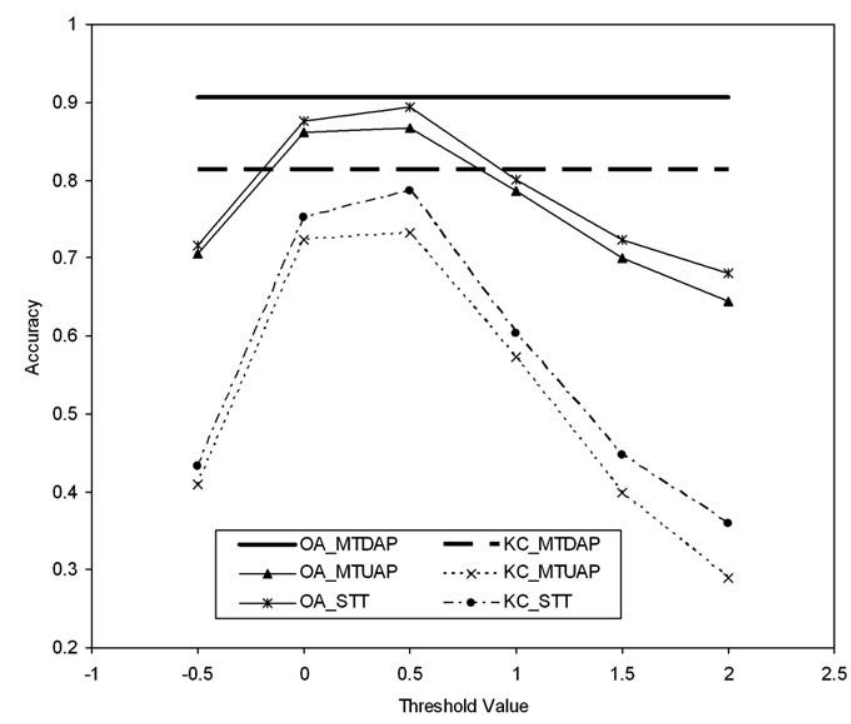

Fig. 10. Accuracy results from using different thresholds in the Seattle area. OA_MTDAP and KC_MTDAP are the overall accuracy and Kappa coefficient obtained from multiple thresholds with different adjustment parameters for different LC types. OA_MTUAP and KC_MTUAP are the overall accuracy and Kappa coefficient obtained from multiple thresholds with one adjustment parameter for different LC types. OA_STT and KC_STT are overall accuracy and Kappa coefficient obtained from a single threshold.
Table 4

Accuracy assessments of land cover classification for the five study areas.

\begin{tabular}{lll}
\hline Location & Overall accuracy & Kappa coefficient \\
\hline Manchester & 83.33 & 0.8179 \\
Jackson & 78.36 & 0.7635 \\
Sioux Falls & 88.57 & 0.8720 \\
Seattle & 78.32 & 0.7614 \\
San Diego & 87.50 & 0.8592 \\
\hline
\end{tabular}

detection (MAD) approach (Nielsen et al., 1998) to calculate multivariate covariance and employed a single threshold determined by chi-square distribution to select time-invariant pixels from bitemporal images. These no-change pixels were then used for performing the actual image normalization. However, the MADnormalization approach may still face challenges when it is used for land cover change detection and change classification. How useful the normalized image for land cover change related change determination is not clear. However, the feasibility of combining MAD-normalization and CVA for change detection needs further investigation.

The method used in this study made distinctions among different land cover change classes by employing different thresholds according to land cover types. This multiple threshold approach performed better than a single threshold approach because the areas of change and no-change were determined by both spectral signals and land cover characteristics. Once change areas are identified, the implementation of DTC enabled quick and efficient labeling of these areas using NLCD 2001 as a baseline.

This new prototype method was developed in five study areas (corresponding to five Landsat scene footprints) across the conterminous United States. Budget limitations necessitated minimizing the number of prototype site selections, and although more than five sites would have been preferable, we feel the five sites selected adequately represent potential land cover characteristic issues. To further test prototype conclusions, a pre-production phase test was implemented by selecting two adjacent Landsat scenes in Colorado for product development. This step both enabled the evaluation of the method in an independent new geography and allowed examination of potential edge-matching issues. Because these scenes contained a significant mixture of forests, grasslands, agricultural land, and urban areas (including the Denver metro area), they extended the test range of the prototyping to represent a total of 22 of 84 (26\%) Level III ecoregions across the conterminous United States (Omernik, 2004). The NLCD 2006 update method performed well in this second phase test, best illustrated by the successful capture of major land cover change over this area initiated by wildland fire and urban land cover expansion. The sensitivity analysis for normalized images suggested that all unchanged areas had insignificant differences at the 95\% confidence level, indicating high similarities between two-date images. The accuracies of LC from the baseline dataset remained when training datasets were obtained from these areas. The results for the validation of the overall LC classification for our pilot areas varied from $88.5 \%$ to $78.3 \%$. In our judgment, this represents reasonable accuracy thresholds for a national product. Because of the success of the CVA-DTC method in efficiently identifying land cover change between 2001 and 2006, we also assume this method would be successful when repeated with other time intervals (annual, biannual, or decadal) and could potentially serve as a tool for land cover change analysis for those seeking to go further back in time using archived imagery - or forward in time using newly acquired imagery. However, the primary potential disadvantage of this approach centers on the potential availability of satellite imagery. The CVA requires that the pair of images be in the same month or the same vegetation growing season. Some areas may not have enough cloud-free images to meet this requirement. One impact of using a non-similar image pair is 
potentially poorer accuracy for change detection and LC classification. The CVA is also satellite sensor dependent. Images from two different sensors may not produce optimum change detections from image normalization. Another limitation of the CVA-DTC approach is the classification accuracy of areas that experience changes in spectral signals but not in land cover type. Most of these classification difficulties occur in agricultural land where many spectral changes could be misidentified as changes of land cover. Also, the spectral change in agricultural land could be misclassified as another type of land cover class that has similar spectral signals. Extra correction procedures are usually needed to keep only persistent changes although they are retained in a minimum level compared with most classifications made by the DTC models.

Despite these limitations, we feel the application of this method to the conterminous US will produce a reasonably accurate and efficient updated 2006 land cover product for several reasons. First, the method semi-automatically identifies land cover change based on relevant information using physically based rules. This provides appropriate objectivity to develop a consistent product with acceptable prediction accuracies. Second, the method creates greater cost efficiencies by targeting land cover patches that require updating, rather than the total area. Finally, the updating method ensures the new 2006 land cover product will be consistent with the NLCD 2001 base product - an essential element for successful land cover change comparison. Readers should be cautioned that although NLCD is determined to produce future updated land cover, this method was specifically designed to update NLCD land cover between 2001 and 2006. Future NLCD land cover products and methods beyond 2006 will consider future requirements and circumstances in the design to deliver the most relevant product for the nation.

\section{Conclusion}

Accurate and up-to-date land cover composition and change are important considerations for a wide variety of applications. However, at regional or national scales, data acquisition difficulties, cost, and inadequate analytical techniques hinder rapid and accurate production. A new method to create an updated version of NLCD for 2006 has been designed to address these specific needs. This prototype method provides a cost-effective and faster way to enable land cover updating. This approach depends upon semi-automated data processing protocols to reduce cost and production times. Methods involve change vector analysis driven by different thresholds based on land cover type rather than a single threshold, coupled with decision tree classification trained from unchanged pixels to label changed pixels to updated land cover. Results obtained from this study demonstrate that this approach is robust and provides products that enable the use of NLCD as a baseline database to monitor land cover change. We anticipate using this approach will significantly reduce cost and production times needed to produce the next version of NLCD in circa 2006. The result will be a more time relevant land cover data layer for the nation, with increasing emphasis on the need for credible land cover composition and change information.

\section{Acknowledgements}

The authors thank Jon Dewitz, Nazmul Hossain, Chris Barnes, and Debbie Meyer for their valuable suggestions and discussions during the method development and testing. We also thank Mike Coan for his early change detection work that provided useful information for our test area selection and Richard Vandersnick for the selection of Landsat images for the study areas. We thank Dr. David Meyer and Mr. Terry Sohl for their reviews and suggestions to the manuscript. Four anonymous reviewers are also thanked for their suggestions that greatly improved the manuscript.

\section{References}

Anderson, J., Hardy, E., Roach, J., \& Witmer, R. (1976). A land use and land cover classification system for use with remote sensor data. U.S. Geological Survey professional paper, vol. 964.28 pp.

Cakir, H. I., Khorram, S., \& Nelson, S. A. C. (2006). Correspondence analysis for detecting land cover change. Remote Sensing of Environment, 102, 306-317.

Canty, M., Nielsen, A. A., \& Schmidt, M. (2004). Automatic radiometric normalization of multitemporal satellite imagery. Remote Sensing of Environment, 91, 441-451.

Chen, J., Gong, P., He, C., Pu, R., \& Shi, P. (2003). Land-use/land-cover change detection using improved change-vector analysis. Photogrammetric Engineering \& Remote Sensing, 69, 369-379.

Collins, J. E., \& Woodcock, C. E. (1996). An assessment of several linear change detection techniques for mapping forest mortality using multitemporal Landsat TM data. Remote Sensing of Environment, 56, 66-77.

Comber, A. J., Law, A. N. R., \& Lishman, J. R. (2004). Application of knowledge for automated land cover change monitoring. International Journal of Remote Sensing, 25, 3177-3192.

Coppin, P. R., \& Bauer, M. E. (1994). Processing of multitemporal Landsat TM imagery to optimize extraction of forest cover change features. IEEE Transactions on Geosciences and Remote Sensing, 32, 918-927.

Coppin, P., Jonckheere, I., Nackerts, K., \& Muys, B. (2004). Digital change detection methods in ecosystem monitoring: A review. International Journal of Remote Sensing, 10, 1565-1596.

Dolan, K., Masek, J., Collatz, J., \& Huang, C. (2007). Analysis of Early Forest Regrowth in the Eastern US using IceSAT/GLAS-LiDAR and Landsat-spectral data. Poster of American Geophysical Union 2007 Fall Conference. San Francisco, CA.

Du, Y., Teillet, P. M., \& Cihlar, J. (2002). Radiometric normalization of multitemporal high-resolution images with quality control of land cover-change detection. Remote Sensing of Environment, 82, 123-134.

Elvidge, C., Yuan, D., Weerackoon, R. D., \& Lunetta, R. S. (1995). Relative radiometric normalization of Landsat multispectral scanner (MSS) data using an automatic scattergram-controlled regression. Photogrammetric Engineering \& Remote Sensing, $61,1255-1260$.

Furby, S. L., \& Campbell, N. A. (2001). Calibrating images from different dates to likevalue counts. Remote Sensing of Environment, 77, 186-196.

Hall, F. G., Strebel, D. E., Nickeson, J. E., \& Goerz, S. F. (1991). Radiometric rectification: Toward a common radiometric response among multidate, multisensor images. Remote Sensing of Environment, 35, 11-27.

Hame, T. H. (1988). Interpretation of forest changes from satellite scanner imagery. Satellite imageries for forest inventory and monitoring; experiences, methods, perspectives, Research Notes No. 21. (pp. 47-60). Helsinki, Finland: Department of Forest Mensuration and Management, University of Helsinki.

Homer, C., Dewitz, J., Fry, J., Coan, M., Hossain, N., Larson, C., et al. (2007). Completion of the 2001 National Land Cover Database for the conterminous United States. Photogrammetric Engineering \& Remote Sensing, 73, 337-341.

Homer, C., Huang, C., Yang, L., Wylie, B., \& Coan, M. (2004). Development of a 2001 national land cover database for the United States. Photogrammetric Engineering $\mathcal{E}$ Remote Sensing, 70, 829-840.

Jensen, J. R., Rutchey, M. S., \& Narumalani, S. (1995). Inland wetland change detection in Everglades Water Conservation Area 2A using a time series of normalized remotely sensed data. Photogrammetric Engineering E' Remote Sensing, 61, 199-209.

Lambin, E. F., \& Strahler, A. H. (1994). Change-vector analysis in multispectral space: A tool to detect and categorize land-cover change process using high temporalresolution satellite data. Remote Sensing of Environment, 48, 231-244.

Loveland, T. R., Sohl, T. L., Stehman, S. L. V., Gallant, A. L., Sayler, K. L., \& Napton, D. E. (2002). A strategy for estimating the rates of recent United States land-cover changes. Photogrammetric Engineering \& Remote Sensing, 68, 1091-1099.

Lu, D., Mausel, P., Brondízio, E., \& Moran, E. (2004). Change detection techniques. International Journal of Remote Sensing, 25, 2365-2407.

Lunetta, R. S., Alvarez, R., Edmonds, C. M., Lyon, J. G., Elvidge, C. D., \& Bonifaz, R. (2002). An assessment of NALC/Mexico land-cover mapping results: Implications for assessing landscape change. International Journal of Remote Sensing, 23, 3129-3148.

Lunetta, R. S., Ediriwickrema, J., Johnson, D. M., Lyon, J. G., \& McKerrow, A. (2002). Impacts of vegetation dynamics on identification of land-cover change in a biologically complex community in North Carolina USA. Remote Sensing of Environment, 82, 258-270.

Lunetta, R. S., Knight, J. F., Ediriwickrema, J., Lyon, J. G., \& Worthy, L. D. (2006). Landcover change detection using multi-temporal MODIS NDVI data. Remote Sensing of Environment, 105, 142-154.

Morisette, J. T., \& Khorram, S. (2000). Accuracy assessment curves for satellite-based change detection. Photogrammetric Engineering \& Remote Sensing, 66, 875-880.

Nielsen, A. A., Conradsen, K., \& Anderson, O. B. (2002). A change oriented extension of EOF analysis applied to the 1996-1997 AVHRR sea surface temperature data. Physical and Chemistry of the Earth, 27(32-34), 1379-1386.

Nielsen, A. A., Conradsen, K., \& Simpson, J. J. (1998). Multivariate alteration detection (MAD) and MAF post-processing in multispectral, bitemporal image data: New approaches to change detection studies. Remote Sensing of Environment, 64, 1-19.

Nelson, T., Wilson, H. G., Boots, B., \& Wulder, M. A. (2005). Use of ordinal conversion for radiometric normalization and change detection. International Journal of Remote Sensing, 26, 535-541.

Omernik, J. M. (2004). Perspectives on the nature and definition of ecological regions. Environmental Management, 34 (Suppl. 1), s27-s38.

Schott, J. R., Salvaggio, C., \& Volchok, W. J. (1988). Radiometric scene normalization using pseudo-invariant features. Remote Sensing of Environment, 26, 1-16. 
Singh, A. (1989). Digital change detection techniques using remotely-sensed data. International Journal of Remote Sensing, 10, 989-1003.

Vogelmann, J. E., Howard, S. M., Yang, L., Larson, C. R., Wylie, B. K., \& Van Driel, N. (2001) Completion of the 1990's National Land Cover Data Set for the conterminous United States from Landsat Thematic Mapper Data and ancillary data sources. Photogrammetric Engineering \&' Remote Sensing, 67, 650-662.
Xian, G., \& Crane, M. (2005). Assessments of urban growth in the Tampa Bay watershed using remote sensing data. Remote Sensing of Environment, 97, 203-215.

Yang, X., \& Lo, C. P. (2000). Relative radiometric normalization performance for change detection from multi-date satellite images. Photogrammetric Engineering \& Remote Sensing, 66, 967-980. 